\title{
UN TEMPLO PARA LA NACIÓN ESPAÑOLA: LA BASÍLICA DEL PILAR (1854-1940) ${ }^{1}$
}

\author{
POR \\ FRANCISCO JAVIER RAMÓN SOLANS \\ Institut d'Histoire de la Révolution française (Université de Paris I \\ Panthéon Sorbonne)
}

\section{RESUMEN}

Basándonos en un análisis en la longue durée, este trabajo pretende observar como el templo del Pilar fue adquiriendo progresivamente un carácter nacional. En una coyuntura particularmente favorable a los cultos marianos, el relato del Pilar fue adaptándose a los nuevos tiempos. El desafío abierto por el Sexenio democrático impulsó el carácter nacional de su templo. Asimismo, el Pilar fue adquiriendo una dimensión histórica y militar a través de su utilización durante la conmemoración de los Sitios y la Guerra del Rif. Sólo teniendo en cuenta este proceso se puede comprender el importante papel que desempeñó su templo durante el franquismo.

\section{PALABRAS CLAVE}

Religión; nacionalismo; política; templos; cultos marianos; Virgen del Pilar.

${ }^{1}$ Este trabajo ha sido posible gracias al apoyo de los proyectos de investigación: «Restauración y monarquía en los orígenes del mundo contemporáneo. España y Europa, 1814-1848» dirigido por Pedro Rújula y «Representaciones de la historia en la España contemporánea: políticas del pasado y narrativas de la nación (1808-2012)» dirigido por Ignacio Peiró. 


\section{A TEMPLE FOR THE SPANISH NATION: THE BASILICA OF OUR LADY OF THE PILAR (1854-1940)}

\section{ABSTRACT}

Based on a long-term analysis, this paper aims to observe how the temple of Our Lady of Pilar was progressively acquiring a national character. Under favorable circumstances to the flourishing of Marian cults, Pilar's tradition was adapting to the changing times. The open challenge by the Democratic six-year period in Spain (1868-1874) drove forward the national character of its temple. Furthermore, due to the commemoration of the Napoleon's siege of Zaragoza and the Rif War, the Pilar took a military and historical turn. Taking into account this process, we can understand the important role played by its temple during the Franco regime.

\section{KEY WORDS}

Religión; nationalism; politics; temple; marian cults; Virgin of the Pilar.

$\begin{array}{ll}\text { Recibido/Received } & 10-10-2011 \\ \text { Aceptado/Accepted } & 16-06-2014\end{array}$

Los lugares de culto están marcados por su polisemia ya que tienen tantos significados como personas los visitan. ${ }^{2}$ Para algunos, se reducen a monumentos o tradiciones; para los fieles representan la casa de Dios, el espacio en el que se expresa la vinculación con un símbolo religioso, fuente de milagros, consuelo o intercesión; para otros remiten a momentos, alegres o tristes, expresados a través de ritos de paso; etc. Los templos sagrados también despiertan pues sentimientos e identidades supraindividuales, ya sean familiares, parroquiales, locales, regionales, nacionales o de otro tipo. Como señalaba Sossie Andézian en un reciente monográfico sobre la fundación de lugares de culto:

Progresivamente, estas construcciones van a delimitar los territorios políticos y a servir de soporte a identidades colectivas, del mismo modo que van a materializar las doctrinas religiosas y expresar las luchas y conflictos entre ellas. Y su más que corriente transformación en lugar de memoria les confiere un poder

2 Esta afirmación esta inspirada en la ambivalencia de los comportamientos y prácticas religiosos subrayada por Certeau, M. 2007. El lugar del otro. Historia religiosa y mística: 34-42 Madrid, Katz. 
simbólico perteneciente al campo de la inmanencia y que tiende a confundir territorio sagrado y entidad política. ${ }^{3}$

Es en este marco interpretativo en el que debe de entenderse la decisión de declarar el Pilar como "Templo nacional y santuario de la Raza", el 30 de diciembre de 1939, tan sólo unos días antes de que comenzaran los fastos por el XIX centenario de la aparición de la Virgen. Este título recogía las aspiraciones de varios prelados y del Ayuntamiento de Zaragoza que habían manifestado que éste "sería un medio idóneo de acrecentar la devoción a la Virgen Santísima del Pilar y agradecerle los innumerables beneficios que nos ha dispensado durante la guerra". ${ }^{4}$ Su templo sintetizaba las virtudes patrióticas, lo más hondo del ser hispánico, las esencias del nuevo credo nacionalcatólico.

Para algunos historiadores, la elección del Pilar como elemento movilizador durante la guerra y el franquismo radicaba evidentemente en su dimensión popular aunque éste no fuera el único factor explicativo. ${ }^{5}$ Sin embargo, también debemos tener en cuenta que estos vínculos emocionales con el lugar y el símbolo sagrado han de ser explicados en clave antropológica y sociológica. Resulta frecuente encontrar casos en los que la comunidad recurría a un lugar sagrado para definirse a sí misma (ad intra) y frente al resto (ad extra). ${ }^{6}$ Por otro lado, este tipo de vinculaciones con un territorio a través de un elemento sagrado está sujeto a las modificaciones que con el paso del tiempo se van

${ }^{3}$ Andézian, S. 2010, "Introduction: procès de fondation", Archives des Sciences Sociales des Religions 151: 10.

${ }^{4}$ Boletín Oficial del Estado, n 364, 30 de diciembre de 1939, pp. 73617363. Para el análisis del centenario ver Cenarro Lagunas, A. 1997. "La reina de la hispanidad: fascismo y nacionalcatolicismo en Zaragoza, 1939-1945", Revista de Historia Jerónimo Zurita 72: 91-101.

${ }^{5}$ Algunos trabajos parten de su popularidad y su vinculación con la Guerra de la Independencia y obvian todo este proceso de construcción ver Cenarro Lagunas, A. 1997: 91-92 o los capítulos consagrados a la Virgen del Pilar por Di Febo, G. 2002. Ritos de guerra y de victoria en la España Franquista: 39-49 Bilbao: Desclée de Brouwer y Di Febo, G. 1988. La Santa de la Raza. Teresa de Ávila: un culto barroco en la España franquista (19371962), Barcelona: Icaria. Una visión más amplia y completa de la utilización del Pilar a lo largo del primer tercio del siglo XX en Peiró Martín, I. y Rújula López, P. 2000. "Representaciones calculadas: La imagen de Aragón en el siglo XX", en C. Forcadell (coord.), Trabajo, sociedad y cultura. Una mirada al siglo XX en Aragón: 275-301 Zaragoza: Publicaciones Unión. Para la historia de la devoción y sus usos políticos y nacionales en la larga duración véase por último Ramón Solans, F.J. 2014. La Virgen del Pilar dice... Usos políticos y nacionales de un culto mariano en la España Contemporánea. Zaragoza: Prensas Universitarias de Zaragoza.

${ }^{6}$ Halbwachs, M. 2008. La topographie légendaire des évangiles en Terre Sainte:124-128 París : PUF. 
introduciendo en esta relación. En el fondo, es lógico pensar que una vez que los lazos de una comunidad fueran reformulados en clave nacional, la Iglesia como parte de ella los reestructurase en clave católica. Así, la historia de un lugar de culto

Está jalonada por momentos de fundación y de refundación. Su vocación cambia en función de contextos históricos y políticos. Manifestaciones concretas de acciones de expansión religiosa, cristalizan tensiones internas y externas, y traducen la dinámica de emergencia de nuevas formas religiosas. Sus usos políticos las sitúan en los cimientos de territorios nacionales o locales y las transforman en mitos de origen de agrupaciones humanas. ${ }^{7}$

Asimismo, para explicar su elección como "basílica de la raza", también habría que tener en cuenta la serie de milagros atribuidos a su intercesión y patronazgo que convertían a su templo en un lugar perfecto para la sacralización de la política y para la sublimación de la nación católica. ${ }^{8}$ Por último, tampoco se puede obviar el importante rol que desempeñó su devoción en la propaganda bélica. El Pilar fue uno de los primeros elementos católicos en ser movilizados para la causa franquista debido al temprano bombardeo del templo el 3 de agosto de 1936, convirtiéndose desde ese momento en un clásico de la retórica franquista. ${ }^{9}$

Sin embargo, hay que ir más allá en las razones de su instrumentalización durante la Guerra Civil. Se debe señalar cuál fue el proceso que llevó a aunar religión y patria en aquel lugar, cómo se resemantizaron sus muros para dotarlos de este carácter de Paladium de la Raza y en qué momento podemos situar el origen de este discurso. A pesar de que el análisis desde la longue durée nos impida ser tan precisos como quisieramos, esta perspectiva nos resulta particularmente interesante para el análisis de la religión y de la tradición ya que permite

\footnotetext{
${ }^{7}$ Andézian, S. 2010: 22.

${ }^{8}$ Para los milagros del Pilar y sus diversas implicaciones véase Ramón Solans, F.J. 2012.

${ }^{9}$ Ramón Solans, F.J., 2011. "«Como Español y católico» los efectos del proceso de contrucción nacional de la Virgen del Pilar (1932 y 1936)", en A. Barrio Alonso, J. Hoyos Puentes y R. Saavedra Arias (coords.), Nuevos horizontes del pasado: culturas políticas, identidades $y$ formas de representación: 9 Santander: Publican; Núñez Seixas, X.M. 2006. ¡Fuera el invasor! Nacionalismo y movilización bélica durante la guerra civil española (1936-1939): 187-188 Madrid: Marcial Pons y Cruz, R. 2005. "Old symbols, new meanings: mobilizing the rebellion in the summer of 1936", en C. Ealham y M. Richards (eds.), The Splintering of Spain. Cultural History and the Spanish Civil War, 1936-1939: 159-176 Cambridge: Cambridge University Press.
} 
quebrar la ilusión de permanencia que generan sus relatos ${ }^{10}$, revelando su carácter histórico y rompiendo con cualquier tipo de definición ontologizante y apriorística de los mismos. Por último, estas perspectiva nos permitirá mostrar la vitalidad y modernidad de la construcción católica de la nación española, frente a aquellos que han visto en la religión un obstáculo para el desarrollo de una idea moderna de nación. ${ }^{11}$

\section{EL “JORDÁN DE LOS ESPAÑOLES" Y EL PILAR COMO "EXVOTO NACIONAL”. 1854-1908}

El siglo XIX ha sido calificado frecuentemente como "el siglo mariano por excelencia" debido a la frecuencia y riqueza de sus manifestaciones. Tras la crisis revolucionaria de 1789-1814, comenzó una fase de revitalización de la Iglesia católica que encontraría su mejor expresión en la recuperación y potencialización de una serie de cultos marianos de gran calado popular con el objetivo de reconquistar a través de esta figura maternal su poder perdido. Este nuevo impulso mariano tuvo una gran variedad de manifestaciones: se volvieron a trazar los caminos de las peregrinaciones, las Iglesias fueron redecoradas y autores claves como san Alfonso María Ligorio o Grignion de Monfort fueron redescubiertos. ${ }^{12}$ El desarrollo de estas nuevas muestras de devoción no hizo sino confirmar como la Virgen se fue convirtiendo a lo

10 Balandier, G. 1993. El desorden. La teoría del caos y las ciencias sociales. Elogio de la fecundidad del movimiento: 93 Barcelona: Gedisa.

11 Estas reticencias se expresan básicamente ante una supuesta incompatibilidad entre el universalismo católico y la nación, incompatibilidad que de existir plantearía similares problemas ante otras propuestas universales como las de los derechos del hombre o el socialismo. Asimismo, esta idea de incompatibilidad también radica en el fondo en la tradicional dicotomía: tradición (Iglesia católica) y modernidad (nación). Esta interpretación ha sido defendida en José Álvarez Junco, J. 2006. "El conservadurismo español: entre religión y nación", en L. Castells (ed.), Del territorio a la nación Identidades territoriales y construcción nacional: 3964 Madrid: Biblioteca Nueva o Suárez Cortina, M. 2008. "Catolicismo,identidad nacional y libertad religiosa en la España liberal”, en J. Beramendi y M.J. Baz, Identidades y memoria imaginada: 223-261 Valencia: PUV, 2008. Una visión crítica de esta aproximación en Ramón Solans, F.J. 2014.

${ }^{12}$ En este sentido, destacaría la obra Glorias de María de Alfonso de Ligorio que se convierten en un auténtico éxito editorial en 1830 y el descubrimiento del Tratado de la verdadera devoción a la Virgen María de Grignon de Montfort escrito en 1712. Ver Langlois, C. 2000. "La conjoncture mariale des années quarante", en F. Angelier y C. Langlois (eds.), La Salette. Apocalypse, pèlerinage et littérature (1846-1996). Actes du colloque de l'Institut catholique de Paris (29-30 de novembre de 1996): 21-38 Grenoble : Jérôme Million. 
largo del ottocento en "una figura ecclesiae en la que se junta populismo y romanismo, tradición y contemporaneidad". ${ }^{13}$

Este movimiento mariano se vio acompañado por el restablecimiento de Pío IX en el solio pontificio tras las revoluciones de 1848 y de un gradual fortalecimiento de la autoridad papal. El Syllabus (1864) y la declaración de la infalibilidad papal (1870) supondrían la culminación de este proceso de declive del galicanismo e impulso de una centralización administrativa. ${ }^{14}$ En este proceso de romanización dogmática, la declaración de la Inmaculada Concepción con la bula Ineffabilis Deus (1854) contribuyó a crear un ambiente propicio para la profusión y exaltación de cultos marianos en Europa además de constituir una buena prueba de la progresiva consolidación de la autoridad papal. ${ }^{15}$ La promulgación de dicho dogma se vería confirmada dentro de la cosmovisión católica por las apariciones de la Inmaculada a una niña llamada Bernadette Soubirous en un pequeño pueblo de los Pirineos franceses en 1858. A la postre, Lourdes se convertiría en uno de los centros devocionales más importantes así como en un referente organizativo para los católicos de todo el mundo. Su éxito estaría mediatizado por su carácter inmaculista así como por el apoyo de los sectores más ultras del catolicismo francés y la necesidad de articular un discurso sobrenatural que hiciera frente de una manera efectiva al positivismo racionalista. ${ }^{16}$

13 Langlois, C. 2005. "Le temps de l'immaculée conception. Définition dogmatique (1854) et événement structurant", en B. Bérthouart y A. Lottin (coords.), La dévotion mariale de l'an mil à nos jours : 366-379, para la cita p. 378 Arras: Artois Presse Université.

${ }^{14}$ Sobre la crisis del galicanismo ver Gough, A. 1996. Paris et Rome, Les catholiques français et le pape au XIX ${ }^{e}$ siècle París: Les éditions de l'Atelier/Éditions ouvrières. Un análisis de este proceso de romanización ver Bruley, Y. 2002. "La romanité catholique au XIXe siècle: un itinéraire romain dans la littérature française", Histoire, Économie et Société 21: 59-70; para la consolidación de la figura del Papa ver Horaist, B. 1995. La Dévotion au Pape et les catholiques français sous le pontificat de Pie IX (1846-1878). D'après les Archives de la Bibliothèque Apostolique Vaticane: 9-22 Roma: École Française de Rome; y para el proceso de centralización ver Bayly, C. A. 2010. El nacimiento del mundo moderno 1789-1914. Conexiones y comparaciones globales: 395-410 Madrid: Siglo XXI.

${ }^{15}$ Ver Langlois, C. 2005 : 366-379. De hecho, estos festejos tuvieron un marcado carácter ultramontano como se puede ver en Sorrel, C. 2001. "Ultramontanisme et culte marial: les fêtes de las promulgation du dogme de l'immaculée Conception dans le duché de Savoie (1855)", en P. d'Hollander (ed.), L'Église dans la rue. Les cérémonies extérieures du culte en France au $X I X^{e}$ siècle. Actes du colloque des 23-24 mars 2000 à Limoges: 229-242 Limoges: Pulim.

${ }^{16}$ Harris, R. 1999. Lourdes. Body and Spirit in the Secular Age: 110-135 
Tras el impacto de la Revolución francesa y en paralelo a este impulso mariano y de centralización romana, la Iglesia fue progresivamente incorporando el discurso nacional como respuesta al principio de nacionalidad liberal-constitucional y al internacionalismo socialista. ${ }^{17}$ A pesar de su centralización romana, la Iglesia se organizaba de manera estatal y los requisitos de su trabajo "forzaron al clero a pensar en ámbitos locales, vernáculos y, cada vez más nacionales". ${ }^{18}$ El catolicismo ofrecía un material muy fértil para futuras construcciones nacionales. Así, por ejemplo, durante la época moderna, se produjo un proceso de territorialización de la devoción del Pilar y de construcción de vínculos identitarios en torno a ella que durante la Guerra de la Independencia permitió asociarla facilmente con la defensa de Zaragoza, Aragón y España. ${ }^{19}$

Por otra parte, la reproducción de modelos religiosos o directamente la inclusión de estos, se puede observar en la "santificación del punto de partida", "mitologización y conmemoración de grandes amenazas contra la identidad nacional", "la provisión de un modelo bíblico para la nación" y por último "el descubrimiento de un destino nacional único". ${ }^{20}$ Entre otras muchas manifestaciones de este espíritu providencial, encontraríamos el proyecto de la Academia bibliográfica mariana de escribir una historia de España en clave mariana para: "demostrar con toda la elocuencia de los hechos como la Santísima Virgen mira a la España, cual herencia y posesión suya, y como la España ha correspondido a sus finezas con toda clase de testimonios de

Londres: Penguin Book y Gugelot, F. 2010. "Les deux faces de Lourdes. Lourdes de Zola et Les foules de Huysmans". Archives des Sciences Sociales des Religions 151: 213-228.

17 Véase para el caso español Vilallonga, B. 2012. "La nación católica: Balmes y la representación de España en el ochocientos, Historia Social 72: 49-64. Un balance actual sobre las relaciones entre nación y religión en España en Louzao Villar, J. 2013. "Nación y catolicismo en la España contemporánea. Revisitando una interrelación histórica". Ayer 90: 65-89. Para la dimensión nacional de los cultos marianos ver Ramón Solans, F. J. 2012. "Movilización, política y nación. Una aproximación historiográfica a los cultos marianos en época contemporánea", Amnis. Revue de civilisation contemporaine Europes/Amériques, 11.

${ }_{18}$ Hastings, A. 2000. La construcción de nacionalidades: etnicidad, religión y nacionalismo: 237 Madrid, Cambridge University Press.

${ }_{20}^{19}$ Ramón Solans, F.J. 2014.

20 Ibidem, p. 232. Para el papel de la religión en las construcciones nacionales ver también Smith, A.D. 2008. Chosen Peoples. Sacred Sources of National Identity: Oxford: Oxford University Press y Haupt, H.-G. y Langewiesche, D. (eds.). 2010. Nación y religión en Europa. Sociedades multiconfesionales en los siglos XIX y XX: Zaragoza: Institución «Fernando el Católico». 
amor y de agradecimiento." ${ }^{21}$ En esta doble dimensión nacional y marial es donde debe entenderse uno de los grandes éxitos de la literatura pilarista: Historia crítica y apologética de la Virgen nuestra señora del Pilar de Zaragoza. Este libro, como señala el propio autor, responde a la necesidad de establecer un nuevo relato de la tradición del Pilar que conforme a "la época actual" ofrezca una versión más sobria, crítica y razonada. ${ }^{22}$

Mariano Nougués elevaba la basílica del Pilar a la categoría de monumento nacional, "un verdadero museo, una gloria nacional, una demostración práctica de nuestros adelantos en las artes, del progreso de nuestros artistas". ${ }^{23}$ Para ello, vinculaba dos momentos centrales de la historia de España, la conquista de Granada (2 de enero) y el descubrimiento de América (12 de octubre) con las dos fechas principales del culto al Pilar, la conmemoración de su aparición y su festividad patronal. ${ }^{24}$ La basílica pasaría así a representar "una gloria común a la España entera del establecimiento del cristianismo, es la significación de un hecho al que debemos nuestra unidad civil, política y religiosa." ${ }^{25}$

Este tipo de proyectos se vio favorecido por los cambios acaecidos en el paisaje español. Tras la caída del bienio progresista y la aprobación de un nuevo concordato, Isabel II se había lanzado en brazos del neocatolicismo como último cartucho para legitimar su deteriorada imagen pública. ${ }^{26}$ Asimismo, en el paisaje zaragozano también habían cambiado las cosas. Entre los años 40 y la primera década del siglo XX, la capital aragonesa iba a experimentar una transformación espectacular.

21 1868. España Mariana. Partido de Lérida: VI Madrid: Academia bibliográfica Mariana, p. VI. Esta defensa de la especial vinculación de la Virgen con un país se puede ver en el caso francés con las obras de Hammon, A. 1866. Notre Dame de France où l'histoire du culte de la sainte vierge en France, depuis l'origine jusqu'à nos jours : París: Henri Plon y Drochon, J.E. 1890. Histoire illustrée des pèlerinages français de la très sainte Vierge: París : E. Plon, Nourrit et Cie.

${ }^{22}$ Nougués y Secall, M. 1862. Historia crítica y apologética de la Virgen nuestra señora del Pilar de Zaragoza y de su templo y tabernáculo desde el siglo I hasta nuestros días: VI-XI Madrid: Imprenta de Alejandro Gómez Fuentenebro.

${ }^{23}$ Ibidem. p. 374.

${ }^{24}$ Con ello, se abría una línea que permitiría reforzar la dimensión católica de la retórica imperialista del nacionalismo español. Ramón Solans, F.J. 2014.

${ }^{25}$ Nougués y Secall, M. 1862: 374.

${ }^{26}$ Burdiel, I. 2003. "La consolidación del liberalismo y el punto de fuga de la monarquía (1843-1870)", en M. Suárez Cortina (ed.) Las máscaras de la libertad. El liberalismo español 1808-1950: 131 Madrid: Marcial Pons. 
La población prácticamente se dobló, alcanzando los 90.000 habitantes. El desarrollo industrial, primero con harineras y textiles y más tarde con azucareras, eléctricas, químicas y otras fábricas, modificaría irremediablemente la morfología urbana. Acompañando este desarrollo económico, se establecería una tupida red de ferrocarriles que conectaría la capital aragonesa con Barcelona, Madrid, Alicante o Cariñena. Todo ello llevaría consigo planes de remodelación del casco urbano, alineaciones de fachadas, aperturas de nuevas calles, la instalación del tranvía o el desarrollo de planes de ensanche que ordenaran el crecimiento de la ciudad. ${ }^{27}$

En este espacio en transformación, la Iglesia zaragozana intentaría mantener su hegemonía simbólica. Para que la basílica del Pilar continuara ocupando un lugar central, su templo debía ser renovado y ampliado. Sus torres y cúpulas debían pugnar con las torres de las chimeneas por el control del skyline de la capital aragonesa. Paulatinamente, la silueta del templo del Pilar, contemplada desde la otra ribera del Ebro y frecuentemente acompañada de dos joteros bailando, se iría convirtiendo en un paisaje sagrado que condensaba las esencias de lo aragonés y español. Como señalaba José Carlos Mainer, todos estos lugares comunes quedarían plasmados en la zarzuela Gigantes y Cabezudos de Miguel Echegaray y Manuel Fernández Caballero, estrenada el 28 de noviembre de 1898:

La segunda escena muestra el Ebro, el puente de Piedra y las siluetas familiares de la Seo y la basílica del Pilar. Y el coro de repatriados canta: «Al fin te veo Ebro famoso...» apostillado por la voz de Jesús, que exclama «Miala, miala Zaragoza...» con no menor convicción que los de Calatorao, cogidos de la mano, han venido en la "perrera» a ver a la Pilarica... Y no faltarán por supuesto, la Procesión del Rosario y el rezo de los protagonistas ante la imagen de la Virgen, reservados para la escena final. Eso va a ser Zaragoza -y, de añadidura, Aragón entero- para la opinión general y en buena medida para la propia: el españolismo acrisolado, la religiosidad fetichista y constantiniana, la exaltación patriótica, la nobleza, la valentía del jaque testarudo $\mathrm{y}$, por supuesto la zafiedad y tosquedad que quieren pasar por sinceridad y llaneza. Una suerte de Andalucía sin duende en versión bufa: dos regiones ambas para el sainete y el chiste. ${ }^{28}$

${ }^{27}$ Forcadell Álvarez, C. 1997. Historia de Zaragoza. Zaragoza en el siglo XIX (1808-1908): 45-78 Zaragoza: Ayuntamiento de Zaragoza.

28 Reflexión de José Carlos Mainer citada en Peiró Martín, I. y Rújula López, P. 2000: 278. Para el regionalismo pilarista ver Ramón Solans, F.J. 2014. 
En el proceso de engrandecimiento de la basílica, este renovado espacio sagrado sería dotado de nuevos significados, el Pilar pasaría a convertirse en el templo de la nación española. ${ }^{29}$ Su caracterización como altar de la Patria hizo que la culminación de sus obras se convirtiera en una empresa nacional. ${ }^{30}$ Desde el siglo XVII, su templo fue objeto de numerosos y ambiciosos proyectos que afectaban tanto a la decoración interna con el proyecto de Ventura Rodríguez o al exterior con el proyecto de torres y bóvedas del marqués de Peralada. Sin embargo, a pesar de su reinauguración formal en 1760, las obras estaban lejos de estar terminadas. La falta de fondos, la Guerra de la Independencia y las convulsiones de la primera mitad de siglo habían impedido su consecución.

Con el acceso a la sede episcopal de Manuel García Gil, un eclesiástico de gran formación que había participado en los momentos claves del papado de Pío IX, se produjo una intensa dinamización del culto del Pilar, especialmente a partir del desarrollo de la bula Ineffabilis Deus (cuya publicación y recepción en España se había visto afectada por el Bienio Progresista). En 1863 consiguió de la Santa Sede la extensión a toda España de la concesión de rezo a la Virgen del Pilar lograda para el reino de Aragón en $1807 .^{31}$ Ese mismo año, se planteó continuar con las obras del templo proyectadas por Ventura Rodríguez en el siglo XVIII gracias a una donación privada. ${ }^{32}$ Un año después, el 8

${ }^{29}$ Para la distinción entre espacios sagrados y profanos ver Eliade, M. 1998. Le sacré et le profane: 25-57 París: Gallimard. Para la idea de centro sagrado ver Hunt, L. 1984. Politics, Culture and Class in the French Revolution: 87-88 Berkeley: University of California Press. Para la constitución de una identidad a través de un lugar ver Augé, M. 2008. Los «no lugares» espacios del anonimato. Una antropología de la sobremodernidad: Barcelona: Gedisa.

30 Numerosos estudios han subrayado el rol de la arquitectura en la construcción de la nación, la importancia del lenguaje arquitectónico como expresión simbólica de la nación. Una reflexión desde la arquitectura en Sudjic, D. 2005. La arquitectura del poder. Cómo los ricos y poderosos dan forma a nuestra mundo: 119-142 Barcelona: Ariel. También estarían los estudios ya clásicos de Mosse, G.L. 2005. La nacionalización de las masas. Simbolismo político y movimientos de masas en Alemania desde las Guerra Napoleónicas al Tercer Reich: 69-100 Madrid: Marcial Pons o Gentile, E. 2007. Fascismo di pietra: Roma: Laterza. Un buen ejemplo práctico sería el estudio del urbanismo y las esculturas en Barcelona de Michonneau, S. 2007. Barcelona. Mémoire et identité. 1830-1930: Rennes: Presses Universitaires de Renne.

${ }^{31}$ Esta concesión dio lugar a tres días de fiesta con asistencia del Ayuntamiento y diversas autoridades públicas, misa solemne en el Pilar, iluminaciones y adornos por toda la ciudad. Archivo Histórico Municipal de Zaragoza (en adelante AHMZ), Gobernación, Funciones públicas, caja 139, expediente $n^{\circ} 837$.

32 Libro de Actas del Cabildo Metropolitano de Zaragoza (en adelante 
de mayo de 1864, se reunirían el Ayuntamiento, el Cabildo, la Universidad, la Diputación y otras corporaciones para crear una Junta de obras que permitiera acometer el proyecto. ${ }^{33}$ Además, la extensión del rezo del Pilar a toda la nación fue utilizada por el Cabildo para legitimar una suscripción de todos los fieles de las diócesis españolas. ${ }^{34}$ En una proclama de 5 de mayo de 1864 el Arzobispo se expresaba así:

...y España toda no puede menos de interesarse por el primero de sus templos, el principio y fundamento de su regeneración social y religiosa, en fin por lo que se ha llamado ya, y es verdaderamente una gloria común, toda una gloria nacional. Creo, pues, hallarme en el caso de apelar al genio y a la piedad nunca desmentida, de los zaragozanos, de los aragoneses todos, y aún de las demás provincias de la nación. ${ }^{35}$

Esta primera remodelación del templo se enmarca en uno de los períodos de construcción de iglesias más importantes de la historia cristiana, tan sólo comparable a la época de las catedrales, la baja Edad Media. ${ }^{36}$ Además, entre 1850 y 1870, se construyeron estatuas gigantes de María por toda la geografía francesa a la vez que se intentaba elevar un santuario nacional en Puy dedicado a Notre Dame de France. ${ }^{37}$ En 1872 la capilla neogótica de Lourdes fue terminada y dos años más tarde, declarada basílica de la Inmaculada Concepción. El templo se convirtió en lugar de la memoria de los enfrentamientos contemporáneos, se llenó de banderas y medallones de la peregrinación nacional de 1872, de los estandartes en desagravio por la guerra franco-prusiana, etc. ${ }^{38}$ Por aquellos años, en París, se terminaba la basílica neobizantina del

LACMZ), 1863, anexos $\mathrm{n}^{\circ} 10$ y 25.

${ }^{33}$ La Cruz, tomo II, 1872, p. 584.

34 Junta de Hacienda del Cabildo Metropolitano de Zaragoza, 12 de agosto de 1863, fol. 216.

${ }^{35} \mathrm{AHMZ}$, Gobernación, General Indiferente, Caja 143, expediente $\mathrm{n}^{\circ}$ 287.

36 Junto con el nacionalismo y el liberalismo, el siglo XIX fue el período de expansión y consolidación de las grandes religiones mundiales. Bayly, C. A. 2010: 419-424.

37 Ver Langlois, C. 2005 : 366-379 y Langlois, C. 1997. "Notre Dame de France (1860), Modernité et identité le succès et l'échec", en E. Fattorini (dir.) Santi, culti, simboli nell'età della secolarizzazione (1815-1915): 301-329 Roma: Rossenberg \& Sellier.

${ }^{38}$ Las obras continuaron con la edificación desde 1883 de una basílica en estilo romano bizantino (similar al del Sagrado Corazón en Montmatre o Notre Dame de Fourvière de Lyon) y terminado a finales de 1880. Este edifico personificaba el estilo estético y espiritual de una era, ecléctico, pesado, imponente, casi industrial. Harris, R. 1999: 169-176. 
Sagrado Corazón, templo expiatorio nacional por la Comuna y la derrota francesa en Sedán. ${ }^{39}$

En España, uno de los ejemplos que más paralelismos puede suscitar con el caso del Pilar sería el de Covadonga. Ambos comparten diseño del arquitecto real Ventura Rodríguez y sus obras quedaron interrumpidas durante más de un siglo. ${ }^{40} \mathrm{~A}$ pesar de que la peregrinación de la reina Isabel II trajo consigo importantes inversiones en carreteras y puentes, el santuario seguía sin terminarse. Fue entonces cuando el obispo de Asturias, Benito San y Flores intentó movilizar a los fieles para la consecución de un templo digno de María que uniera a los católicos en defensa de la unidad histórica de la patria y la fe. Al igual que en el Pilar, la consecución de misa propia en 1873 sirvió de pretexto para fomentar unas obras que consiguieron el respaldo definitivo con la declaración de monumento histórico en 1884 y una subvención anual de 80.000 pesetas. $^{41}$

Las fiestas de la consagración del templo del Pilar, el 12 de octubre de 1872 se celebraron en un ambiente bastante tenso ya que coincidieron con el levantamiento carlista y los problemas de Amadeo de Saboya para consolidar su poder. A esta situación tensa de por sí hay que unir que el periodo del Sexenio democrático se caracterizó por una gran agitación política y social así como por la incipiente organización obrera. ${ }^{42}$ En este sentido, habría que añadir los inicios de una política secularizadora y la aparición de algunos actos anticlericales. Todo ello se configuraba dentro de un marco de guerra cultural o kulturkampf que estaba redefiniendo las relaciones de los diversos estados con la Iglesia. ${ }^{43}$ Este contexto decantó a los eclesiásticos hacia la movilización

${ }^{39}$ Jonas, R. 2000. France and the Cult of the Sacred Heart. An Epic Tale for Modern Times: Los Angeles: University of California Press.

${ }^{40}$ El templo se quemó en 1777 y Campomanes inició una campaña para su reconstrucción de la basílica pero las obras quedaron interrumpidas en los cimientos.

41 Boyd, C.P., 2007. "Paisajes míticos y la construcción de las identidades regionales y nacionales: el caso del Santuario de Covadonga", en C. P. Boyd (coord.), Religión y política en la España contemporánea: 271-294 Madrid: Centro de Estudios Políticos y Constitucionales, 2007, pp. 271-294.

${ }^{42}$ Una visión de conjunto de este período en Callahan, W.J. 1989. Iglesia, poder y sociedad en España, 1750-1874: 241 Madrid: Nerea.Ver asimismo el reciente balance de Fuente Monge, G. 2001. "El enfrentamiento entre clericales y revolucionarios en torno a 1869", Ayer 44: 127-150.

${ }^{43}$ Clarck, C. y Kaiser, W. 2003. Culture wars. Secular-Catholic Conflict in Nineteenth Century Europe: Cambridge: Cambridge University Press. Un buen ejemplo de las consecuencias de estas nuevas políticas estatales y la revitalización de los cultos sería el de las apariciones de Marpingen, Blackbourn, D. 1993. Marpingen. Apparitions of the Virgin Mary in bismarckian 
de los católicos contra la libertad de cultos y la laicización de la nación. Tanto el templo como las ceremonias vinculadas al Pilar serían resemantizadas y pasadas por un tamiz nacional para reivindicar la catolicidad de España.

Un buen ejemplo de este tipo de movilización sería la articulación de la primera peregrinación nacional al Pilar en 1880 siguiendo el modelo de Lourdes. Utilizando toda una serie de recursos modernos (como por ejemplo el ferrocarril, los medios de comunicación o la fotografía), la Iglesia zaragozana planteaba una manifestación pública de fe, bajo el grito de "¡Españoles! ¡Al santuario del Pilar de Zaragoza!". ${ }^{44}$ El Faro católico aragonés afirmaba en este sentido que "ES INDUDABLE. España es una nación católica, eminentemente católica." ${ }^{45}$ Esta ceremonia se articuló a manera de desagravio por la apertura de una iglesia protestante en Zaragoza durante el Sexenio, lo que suponía la ruptura del principio católico de la nacionalidad española:

España, la España católica protestó (...) Una de estas protestas, una de estas profesiones públicas de fe está próxima a verificarse, y los piadosos católicos que a la voz de un eminente y virtuoso prelado han de llevarla a efecto, han elegido por sitio nuestra ciudad y por objeto de ella la Santísima Virgen del Pilar que es nuestra especial patrona. ${ }^{46}$

En definitiva, observamos cómo se pasa de la idea de una nación privilegiada por el Pilar a la idea de un templo donde la comunidad demostraba su españolidad. Una articulación de una identidad nacional católica que en la mayor parte de las ocasiones adquirió un carácter combativo e incluso tonalidades martiriales. Así, no es extraño encontrar declaraciones del siguiente tenor "vamos, pues, humildemente con las armas de la fe, de la caridad y de la oración a pelear las batallas del señor con el clamor de los antiguos caudillos españoles: ¡Santiago y cierra España! Y cuando susciten el último incendio, levantemos el grito bendiciendo a la Virgen del Pilar." ${ }^{47}$

Germany: Oxford: Oxford University Press.

${ }^{44}$ El Faro católico aragonés, $n^{\circ} 16,21 / 01 / 1880$. Un análisis más extenso de esta peregrinación y su contenido nacional en Ramón Solans, F.J. 2011b. "La restructuración del culto al Pilar. La peregrinación de 1880, un proyecto nacional", en C. Frías, J.L. Ledesma y J. Rodrigo (eds.), Reevaluaciones. Historias locales y miradas globales. Actas del VII Congreso de Historia Local de Aragón: 283-292 Zaragoza, Institución «Fernando el Católico».

45 El Faro católico aragonés, n $86,15 / 04 / 1880$.

46 Ibidem.

47 Moreno Mazón, J. 1880, Sermón predicado por el Ilmo. Sr. Dr. José Moreno Mazón en el templo metropolitano del Pilar de Zaragoza el 17 de abril del presente año de 1880: 17 Cuenca: Imp. de Casimira Madina. 
La crisis de 1898, y el subsiguiente debate que ocasionó, acentuó esta dimensión patriótica del catolicismo. Muchos religiosos señalaron que el camino de la regeneración era eliminar esas ideas extranjeras que había corrompido al ser nacional y volver sobre los católicos pasos de los antepasados. ${ }^{48}$ Según esta lectura, los españoles se habían apartado de la religión, que tantas glorias les había dado desde que la Virgen del Pilar pusiera sus pies en Zaragoza, "dejando a España sin Dios,/ sin colonias y sin pan". ${ }^{49}$ En definitiva, para los católicos, el "Desastre fue interpretado en clave providencialista como castigo divino por el desvío liberal de la nación, y ocasión para rectificar en un sentido íntegramente católico, es decir, radicalmente antiliberal". ${ }^{50}$

La celebración del jubileo por el nuevo siglo y los consiguientes enfrentamientos con los anticlericales reforzaron todavía más la lectura nacional del templo del Pilar a través de la idea de desagravio. ${ }^{51}$ El 17 de julio de 1901, la procesión fue interrumpida por gritos y cánticos de la Marsellesa. La situación se volvió aún más tensa con el cruce de disparos, piedras y golpes en la plaza de San Felipe, lugar donde estaban refugiados los penitentes. Según apuntaron algunas fuentes, una parte de la manifestación anticlerical se dirigió hacia el Pilar para apedrearlo, razón por la cual fue cerrado. ${ }^{52}$ Sin embargo, el polémico profesor y periodista católico, Juan Moneva y Puyol hablaba más bien de un simple juego de niños que se tiraban piedras a la puerta de la Basílica. ${ }^{53}$ El 20 de julio, la revista El Pilar consideraba el cierre de la basílica como un acto nunca visto, ni siquiera durante los peores momentos de asedio napoleónico fue cerrada la Basílica del Pilar. Sin

${ }^{48}$ Un buen resumen de estos últimos años del siglo en Callahan, W. 2002. La Iglesia Católica en España (1875-2002): 47-58 Barcelona: Crítica.

${ }^{49}$ Ram de Viu, L. 1908,. "Mi corona", en F. Jardiel, Álbum poético de la Virgen Santísima del Pilar: 135 Zaragoza: Mariano Salas.

${ }^{50}$ Cueva Merino, J. y Montero, F. 2000. "Clericalismo y anticlericalismo en torno a 1898. Percepciones recíprocas", en R. Sánchez Mantero (ed.), En torno al "98". España en el tránsito del siglo XIX al siglo XX. Tomo II: 60 Huelva: Prensas de la Universidad de Huelva. Ver también Boyd, C.P. 2000. Historia Patria. Política, historia e identidad nacional en España: 1875-1975: 102 Barcelona: Editorial Pomares-Corredor.

51 Para la nacionalización del conflicto clericales-anticlericales ver Louzao Villar,, J. 2008. "«Es deber de verdadero y auténtico patriotismo...»: la nacionalización del conflicto entre clericales y anticlericales (1898-1939)", M.E. Nicolás Marín y C. González Martínez (coord.), Ayeres en discusión (recurso electrónico): 73 Murcia: Universidad de Murcia.

52 Salomón Chéliz, M.P. 2002. Anticlericalismo en Aragón. Protesta popular y movilización política (1900-1939): 264-269 Zaragoza: Prensas Universitarias de Zaragoza.

${ }^{53}$ Moneva y Pujol, J. 1952. Memorias: 355 Zaragoza: Noticiero. 
embargo, en ese mismo número, al criticar al Gobernador por no haber disuelto al grupo que lanzaba piedras, confirmaban sin querer la tesis de Moneva y Puyol cuando decían que "causó el efecto más irrisorio que cuando el gobernador partió de la plaza del Pilar fuera aplaudido por unos seis o siete chiquillos, de ocho a doce años, muchos de los cuales acababan de apedrear el templo de la Virgen". ${ }^{44}$ Los católicos zaragozanos exageraron, consciente o inconscientemente, lo acontecido para presentar un clima de persecución que sirviera como elemento movilizador. De hecho, Juan Moneva y Puyol recordaba como su confesor de aquel día, mosén Juan Buj, le exhortó como si se dispusiese, "no para procesión, sino para batalla o para martirio". ${ }^{55}$ Este polémico catedrático de derecho desaprobaba la decisión de cerrar el templo ya que opinaba que "la opinión anticlerical o antirreligiosa no iba contra el Pilar". ${ }^{56}$

Sea como fuere, este acontecimiento alimentó la movilización católica a través del desagravio por lo que ellos entendían como la mayor afrenta que había sufrido el templo del Pilar, una catedral que no había sido nunca cerrada ni siquiera en los tiempos de los "moros" y los franceses. En la circular del Arzobispo para la continuación de las obras decía que "ni en los tiempos de las persecuciones romanas, ni aún en la época de dominación mahometana, ni durante los famosos sitios de 1808 y 1809 , ni en ninguna de las revueltas políticas del siglo XIX, se vieron cerradas las puertas del santuario del Pilar". ${ }^{57}$ Este elemento sirvió para legitimar dos ceremonias de desagravio, la construcción de una torre en el Pilar y la coronación canónica de la Virgen, así como para la creación de una asociación devocional femenina pilarista, la Corte de Honor.

En 1901, "como un acto de desagravio a nuestra dulcísima Madre y Excelsa Patrona por los inauditos atropellos y ultrajes que realizó una turba de desgraciados", se creó una comisión de católicos con el objetivo de realizar una subscripción nacional para terminar la basílica, un proyecto que al final se redujo a la construcción de la segunda torre del templo. ${ }^{58}$ Ese mismo año, la Junta Central de Madrid manifestó su voluntad de preparar una peregrinación nacional en desagravio pare pedir "misericordia y favor para nuestra desgraciada patria". ${ }^{59}$

${ }^{54}$ El Pilar [en adelante EP], 20/07/1901.

${ }^{55}$ Moneva y Pujol, J. 1952: 349.

56 Ibidem, p. 255.

${ }^{57}$ Jardiel, F. 1902. La Virgen del Pilar y su templo. Crónica oficial de las nuevas obras del templo metropolitano de Nuestra Señora del Pilar: 104 Zaragoza: Mariano Salas.

58 LACMZ., 6 de septiembre de 1901, fol. 37.

${ }^{59}$ LACMZ., 19 de septiembre de 1901, fol. 39. 
Finalmente dicha peregrinación se celebró entre el 19 de mayo y el 8 de junio de 1905 con motivo de la coronación de la Virgen del Pilar. Las coronaciones canónicas habían sido un recurso muy útil a la Iglesia católica para invocar a las masas europeas. ${ }^{60}$ Frente a otras coronaciones de carácter local o regional, el cronista de la peregrinación, señalaba que ésta sería nacional ya que "la Virgen Santísima del Pilar, siendo la Reina de España, como va dicho, debe ser coronada y aclamada y obsequiada y festejada y adorada por los Españoles todos." 61 En un sentido muy similar el propagandista católico antiliberal, Sardá y Salvany, subrayaba que:

si cada uno de nuestros antiguos reinos, y aún cada comarca de ellos, tiene su respectivo Santuario Patronal levantado a la Reina de los cielos, la nación entera tiene como suyo propio ese del Pilar, al que, y no a otro alguno, cabe llamar a boca llena con el glorioso título de Santuario Nacional. Lo que Covadonga para Asturias, y Montserrat para Cataluña, y los Desamparados para Valencia, y Begoña para Vizcaya, y los Reyes para Andalucía, eso y mucho más es el Pilar para toda España. ${ }^{62}$

Ante el atentado al Pilar, la peregrinación se presentaba como un "voto nacional" en señal de desagravio. ${ }^{63}$ El obispo de Jaén señalaba que la imagen del Pilar era como un "exvoto nacional" que reunía a un mismo tiempo "nuestras tradiciones religiosas y nuestras glorias patrias". No sólo el propio templo adquiría una dimensión nacional sino también el paisaje que le rodeaba. Así, el río Ebro, parte fundamental del relato pilarista, puesto que a sus orillas se apareció la Virgen a Santiago, se consideraba como "el Jordán de los Españoles". 64

60 Hollander, P. y Langlois, C. (dirs.) 2011. Foules catholiques et régulation romaine. Les couronnements des vierges de pèlerinages à l'époque contemporaine: Limoges : Pulim. Para el caso español véase Ramón Solans, F.J., 2011c. "Le couronnement de la Vierge del Pilar en 1905: une alliance scellée entre le projet national conservateur et le catholicisme", en P. Hollander y C. Langlois (dirs.), Foules catholiques et régulation romaine. Les couronnements des vierges de pèlerinages à l'époque contemporaine : 177188 Limoges : Pulim, 2011. Para la relación de estas ceremonias marianas con el culto eucarístico y al Sagrado Corazón véase Cueva Merino, J. 2000. "Católicos en la calle: la movilización de los católicos españoles, 1899-1923", Historia y Política 3: 55-79.

61 Magaña Soria, A. 1906. Crónica de las solemnes fiestas que se celebraron en Zaragoza con motivo del Fausto suceso de la Coronación Canónica de la Imagen de Nuestra Señora del Pilar y de la Peregrinación Nacional a su Basílica: 50 Zaragoza: Mariano Salas.

62 EP, 13/05/1905.

${ }^{63}$ Magaña Soria, A. 1906: 41-42.

${ }^{64}$ Anexo en Ibidem, p. 12. 
En el fondo, la Virgen del Pilar "se ofrecía a España como una esperanza de regeneración". ${ }^{65}$ Una regeneración doble de la religión y de la patria conseguida gracias a esta romería y cuya labor debía ser continuada. Así, el propagandista católico y jesuita vasco, Remigio Vilariño Ugarte, escribía en El Mensajero del Corazón de Jesús un decálogo para desarrollar este proyecto católico y español. En primer lugar, habría que realizar anualmente una peregrinación nacional al Pilar siguiendo el modelo de Lourdes y hacer de su fiesta, el doce de octubre, un día de celebración para toda España. ${ }^{66}$ Para ello, era necesario agrandar la estación de tren y preparar el interior y exterior del templo. Además, había que vincular el culto al Sagrado Corazón con el del Pilar para constituir "el gran centro de nuestra piedad española, el monumento de nuestras dos mejores devociones, el templo del Corazón de Jesús que reinará y el de la Virgen del Pilar que reina ya coronada entre la Iglesia española". 67

\section{LA BASÍLICA DEL PILAR COMO TEMPLO DE LA HISTORIA NACIONAL}

La celebración del Centenario de los Sitios en 1908 no vino sino a consolidar este relato nacional a través de una lectura del pasado en clave providencial. ${ }^{68}$ Esta percepción histórica se había visto ratificada con la declaración del Pilar como monumento nacional en 1904. La Real Academia de la Historia dio un informe favorable en el que exaltaba el rol que había desempeñado el templo durante los Sitios de Zaragoza. Y es que a pesar de no ser un castillo o una fortaleza, los efectos que había producido su culto revelan "cuán patriótica, cuán gloriosa y útil ha sido la acción de nuestros antepasados al dejarse llevar del fervoroso entusiasmo que inspira el culto a la Virgen, patrona de la ciudad del Ebro". 69

Estos mismos impulsos nacionalistas llevaron en 1906 al arquitecto Félix Navarro a querer plasmar en la geografía sagrada zaragozana la vinculación de los Sitios con el templo del Pilar. El proyecto pretendía que la basílica fuera aislada con una columnata que la rodeara y separara del Ebro ya que a pesar de que "por la tradición y por la poesía nacional viven unidos" es necesario evitar "que el peligroso beso de uno y otro no destruya el sano cúmulo de vida histórica, allí tan

${ }^{65} E P, 10 / 06 / 1905$.

${ }^{66} E P, 10 / 07 / 1905$.

${ }^{67}$ Ibidem.

68 Peiró Martin, I. 2008. La Guerra de la Independencia y sus conmemoraciones (1908, 1958 y 2008): 50 y ss. Zaragoza: Institución «Fernando el Católico».

${ }^{69}$ Gaceta de Madrid, no 181, 29 de junio de 1904, pp. 1221-1222. 
deliciosamente reflejado en el espejo del río". ${ }^{70}$ Cada columna recordaría mediante un escudo a una ciudad hispanoamericana mientras que la cúpula representaría las glorias nacionales. Todo ello sería coronado por un cupulino "para acentuar el carácter de unidad" que teñiría la sala con los colores de la bandera española. ${ }^{71}$ Las regiones estarían representadas en el interior de la bóveda mediante estatuas colosales femeninas, ostentando en sus brazos su respectiva advocación de la Virgen (Montserrat, Covadonga...) y presididas por el Pilar "la primera $u$ original determinación cristiana del culto de María". ${ }^{72}$ Las vidrieras representarían "la magna epopeya religiosa hispana" contra el Islam, el protestantismo y Napoleón. ${ }^{73}$ Por último, se crearía una gran vía sacra que vendría desde el paseo de la Independencia, pasando por el monumento a los mártires de la patria y la religión y finalizando por la creación de una avenida del Pilar que acabaría en la plaza de las catedrales, ampliada para concentrar a las masas.

Este proyecto fue encargado por el arzobispo de Zaragoza que lo utilizó para reivindicar que el monumento de los Sitios fuera la culminación del Pilar. En su pastoral sobre la conmemoración de 1808 recalcaba que la basílica "fue en los días mismos de los Sitios hospital de sangre y recinto donde templaban su valor y heroísmo los defensores de Zaragoza". Proponía además que se construyera un gran faro en la cúpula que alumbrara a unos treinta kilómetro para así proclamar "el mundo transfigurado por la influencia del cristianismo en el Templo de Nuestra Señora del Pilar, santuario nacional conmemorativo de los Sitios". ${ }^{74}$ Aunque por razones económicas nunca se llevara a cabo, proyectos de este tipo nos muestran una clara voluntad de aunar religión y patriotismo en un gran "santuario nacional".

Además, con la finalización de la segunda torre, la silueta del Pilar había sido fijada simbólicamente en la mente de los zaragozanos. Aunque no se construyera ningún faro que iluminara Zaragoza, las torres de la basílica se convertirían en: "tutelares armónicos de la chimeneas fabriles, sea su templo vista amorosa para el labrador de la vega y sus campanas alegría del monte y del prado ribereño del Ebro; sea siempre el foco de luz y de favor para la España nueva, para Aragón glorioso, resucitado a la vida del progreso por la Fe y de la Fe para el progreso". ${ }^{75}$

${ }^{70}$ Navarro, F. 1906. El monumento a los Sitios con el templo del Pilar de Zaragoza: 5 Zaragoza: Mariano Salas.

${ }^{71}$ Ibidem, p. 10.

72 Ibidem, p. 13.

73 Ibidem, p. 14.

74 Soldevila y Romero, J. 1906. Pastoral de.... con respecto a los Sitios de Zaragoza: 13-14 Zaragoza: Mariano Salas.

75 Jardiel, F. 1902: 24. 
Como vimos para la peregrinación de 1880 , la Iglesia no tuvo ningún problema para recurrir a nuevas tecnologías siempre y cuando éstas estuvieran guiadas por valores cristianos. Estos principios católicos se representarían en una pugna por la preeminencia simbólica del skyline zaragozano y se manifestarían en una preocupación por encontrar las formas más apropiadas para inscribirse en el paisaje urbano. ${ }^{76}$

Nada más terminar las ceremonias por la Coronación de 1905, la revista El Pilar marcaba el Centenario de los Sitios como el siguiente objetivo del catolicismo zaragozano. Para ello pediría la colaboración como "buen cristiano y buen patriota" ya que lo que se iba a conmemorar era el triunfo de la defensa de "la independencia nacional" y de "las patrias tradiciones" que fue "inspirado por la religión y por la religión sostenido". ${ }^{77}$ Tan sólo un año después, en 1906, el Arzobispo volvería sobre la cuestión de la conmemoración del centenario intentando aprovechar la ocasión para que se reconstruyera el Pilar como "Monumento Nacional conmemorativo de los Sitios" y del "destino providencial de España". La basílica se convertiría así en el símbolo de una nación católica triunfante ante los sarracenos, los protestantes y finalmente contra "el materialismo francés" ${ }^{78}$

Cuando llegue el centenario de la Guerra de la Independencia la revista El Pilar, el deán de la Catedral y propagandista Florencio Jardiel, el arzobispo Soldevila y otros importantes dirigentes católicos no dudaran en vincular los Sitios con la mitología pilarista. ${ }^{79}$ En aquellos años, se estaba dando forma al paisaje histórico de la Virgen del Pilar aprovechando esta oportunidad conmemorativa. De todos los actos celebrados por el Centenario, no había ninguno "tan digno, tan elevado y tan severo" como las honras fúnebres del 15 de junio de 1908 celebradas

${ }^{76}$ Una pugna muy parecida en el París del Sagrado Corazón y la Torre Eiffel. Jonas, R. 2000: 184-186. Para la idea de la búsqueda de formas de inscribirse en el paisaje urbano ver las reflexión sobre las estatuas gigantes en Langlois, C. 1997: 316. Para el caso español véase las reflexiones de Boyd, C.P. 2007 y Louzao Villar, J. 2011. Soldados de la fe o amantes del progreso. Catolicismo y modernidad en Vizcaya (1890-1923): 207-217 Logroño: Genueve.

77 "Por el Centenario de los Sitios" artículo aparecido en EP, 17/06/1905.

${ }^{78}$ Soldevila y Romero, J. 1906: 8-13.

${ }^{79}$ Peiró Martin, I. 2008: 51-58. Una visión de conjunto del centenario y de la exposición hispano francesa de 1908 y de las pugnas entre los proyectos conservador y progresista en Forcadell Álvarez, C. 2008. "El Centenario de los Sitios y la Exposición Hispano-Francesa. Políticas de la memoria en la Zaragoza de 1908", Libro de Oro de la Exposición Hispano Francesa de 1908: 1-21 Zaragoza: Institución «Fernando el Católico» y Moreno Luzón, J. 2004. "Entre el progreso y la Virgen del Pilar. La Pugna por la memoria en el centenario de la Guerra de la Independencia”, Historia y política 12: 41-78. 
en el Pilar. Florencio Jardiel realizaba una lectura histórica del templo vinculando pasado con presente, patriotismo y religión, pues en ningún sitio como en esa basílica:

se llega a la formal inteligencia de aquellas hazañas gloriosísimas ejecutadas por nuestros padres, a la feliz y cumplida penetración de los motivos que determinaron su realización estupenda, a sentir, como sintieron ellos, del amor a la patria, de su augusta y soberana majestad y de los sacrificios que exige, a la fusión, en fin, de sus almas con nuestras almas... ${ }^{80}$

Por último, aunque su desarrollo desborda los objetivos de este artículo, el culto al Pilar también se había vinculado a una lectura imperial del pasado nacional gracias a la coincidencia de la fecha de su festividad con la del descubrimiento de América. En noviembre de 1908, por iniciativa del obispo de San Carlos de Ancud (Chile), Ángel Jara se depositaron 19 banderas de repúblicas latinoamericanas en el Pilar después de haber sido bendecidas por el papa. Ceremonia que se completó en mayo de 1909 con la bandera de España enviada por Alfonso XIII. La Acción Social Católica zaragozana acordó celebrar esta efeméride anualmente, exaltando el Imperio y su vinculación espiritual con España. ${ }^{81}$

\section{EL PILAR "CASTILLO INTERIOR DE LA PATRIA": ÁFRICA, PRIMO DE RIVERA Y FRANCO}

Como la Virgen del Pilar es de España, España es de la Virgen del Pilar ${ }^{82}$

Declaración de Franco a la revista $\mathrm{La}$ Medalla Milagrosa en 1940.

La significación militar de la Virgen estaba ya presente en su proceso de tradicionalización desde el siglo XVII. ${ }^{83}$ Este carácter bélico se había ido consolidado con el rol que se le atribuyó en la defensa de

${ }^{80}$ Sermón incluido en Jardiel, F. 1920. Algunos sermones, discursos, artículos y poesías: 197 Zaragoza: Salvador Hermanos.

${ }^{81}$ Para la fiesta de las banderas y el pilarismo americanista ver Ramon Solans, F.J. 2014: 237-242. Para la dimensión americana del Pilar ver también Marcilhacy, D. 2010. Raza hispana. Hispanoamericanismo e imaginario nacional en la España de la Restauración: 325-583 Madrid: Centro de Estudios Político Constitucionales y Barrachina, M.A. 2000. "12 de Octubre: Fiesta de la raza, Día de la Hispanidad, Día del Pilar, Fiesta Nacional”, Bulletin d'histoire contemporaine de l'Espagne 30-31: 119-134.

${ }^{82}$ Cit. en Gutiérrez Lasanta, F. 1978. Historia de la Virgen del Pilar. Tomo VII: España y la Virgen del Pilar: 187 Zaragoza: Noticiero.

${ }^{83}$ Ver Ramon Solans, F.J. 2012. 
los Sitios y la concesión de los honores de Capitán General en el Centenario de la Guerra de la Independencia. Sin embargo, fue la guerra del Rif la que la situó en la vanguardia de la simbología religiosa en el ejército con la atribución de la victoria del Monte Gurugú a su intercesión y las campañas propagandistas desarrolladas en Zaragoza por los católicos sociales. ${ }^{84}$ Con la llegada de la dictadura de Primo de Rivera, Marruecos ocupó un lugar central en la liturgia nacionalcatólica que el nuevo régimen estaba desarrollando. Estos rituales le permitieron atribuir a las campañas africanas un carácter de misión providencial como baluarte de la civilización cristiana, papel que, según esta lectura nacionalcatólica, España siempre había tenido. ${ }^{85}$

Dos celebraciones muestran perfectamente el éxito de la campaña para legitimar el proyecto africanista a través del Pilar. Para ello, la Iglesia contó no sólo con la aquiescencia sino con la iniciativa directa de las autoridades primorriveristas. Así, los héroes de Kudia Tahar fueron homenajeados con una guardia de honor el día 12 de octubre en la Santa Capilla y el Altar Mayor de la basílica. ${ }^{86}$ Unos días antes, el omnipresente alcalde Miguel Allué Salvador destacaba la religiosidad de un Primo de Rivera que ha decidido "ofrendar a nuestra excelsa Patrona las flores más preciadas del heroísmo patrio". Y es que en "estos días de bélicas resonancias", España debe de volver la vista a la fe que alentó las gestas de América, Granada, Lepanto y Orán. Parafraseando a santa Teresa, el alcalde destacaba "el hermoso simbolismo del Pilar en la hora presente: el Pilar es el castillo interior de la Patria". ${ }^{87}$

La definitiva victoria en el Rif fue el momento álgido de esta retórica africanista de las virtudes patrias del Pilar. El lugar central de la celebración nacional fue Zaragoza y a sus ceremonias asistieron la infanta Isabel, el dictador Primo de Rivera y el general Sanjurjo. Las exequias por todos los soldados muertos desde 1909 se celebraron en la

${ }^{84}$ Para las campañas africanistas ver Pérez, N. 1930. Apuntes históricos de la devoción a Nuestra Señora La Santísima Virgen del Pilar: 299-318 Zaragoza: Imprenta "La Editorial".

${ }^{85}$ Para la importancia de África en la legitimación del discurso de Primo de Rivera ver Adagio, C. 2004. "Una liturgia per una nazione cattolica. La Chiesa spagnola e le letture provvidenzialiste della dittatura (1923-1930)", en D. Menozzi y R. Moro (ed.), Cattolicesimo e totalitarismo. Chiese e culture religiose tra le due guerre mondiali (Italia, Spagna, Francia): 171-196 Brescia: Morcelliana; Adagio, C. 2004. Chiesa e nazione in Spagna. La dittatura di Primo de Rivera (1923-1930): 148-159 Milán: Unicopli y Quiroga Fernández de Soto, A. 2008. Haciendo españoles. La nacionalización de las masas en la Dictadura de Primo de Rivera (1923-1930): 87-88. Madrid: Centro de Estudios Políticos Constitucionales.

\footnotetext{
${ }^{86} E P, 10 / 10 / 1925$ y $17 / 10 / 1925$.

${ }^{87} E P, 10 / 10 / 1925$.
} 
Santa Capilla, siendo declarado el 12 de octubre fiesta conmemorativa nacional. De esta manera, la basílica concentraba heroísmo, martirio, muerte y patriotismo a la vez que se convertía otra vez en un lugar de exaltación de las victorias militares. ${ }^{88}$

Este carácter bélico de la Virgen se reforzaría con la apertura de la Academia Militar ya que "desde el primer día, el espíritu del centro iba a encontrar en la mistificación españolista creada por la imaginería del Aragón heroico uno de los pilares sobre los que asentar la construcción de una idea de España, unívoca y excluyente". ${ }^{89}$ El día de su inauguración, un aviador lanzó miles de octavillas del alcalde Miguel Allué Salvador que decían "la Patria nos ha confiado, como un sagrado depósito, la Academia en la que ha de formarse el espíritu de sus futuros defensores, que acaban de ofrendar a la Virgen del Pilar su primera oración de soldados". ${ }^{90}$ El periodista y erudito local Gregorio García Arista dedicaba una copla al general Franco el día que inauguraban una calle con su nombre: "Bajo tus expertas manos/Y a la sombra del Pilar/Será patriota y baturra / La Academia Militar". ${ }^{91}$

Y es que Franco conoció desde un principio las virtudes patrióticas de la Virgen ya fuera por las campañas de la publicística pilarista en África o por el reconocimiento que Alfonso XIII le mandaba durante los funerales del jefe del Tercio Rafael Valenzuela en el Pilar. ${ }^{92}$ Durante los años que fue director de la Academia Militar, Franco participó en ocasiones de la vida cotidiana de una capital de provincias. Junto con sus amigos Francisco Urzáiz y Leonor Sala, que años más tarde donarían las dos últimas torres de la basílica o con los Condes de la Salceda iban a cenar a la Maravilla, al teatro o a misa en el Pilar. ${ }^{93}$

El 24 de junio de 1929, la nueva promoción de cadetes se postraba en la Santa Capilla para ser "espiritualmente armados caballeros de la Virgen del Pilar". Una generación de militares, que junto con la vieja élite africanista participaría en la guerra civil, homenajeaba a la Virgen cubierta con el manto de Capitán General y la Corona de 1905. La

${ }^{88}$ EP, 15/10/1927 y 22/10/1927 y Pérez, N. 1930: 313-314.

${ }^{89}$ Peiró Martin, I. 2008: 96.

90 Citado en Blasco ljazo, J. 1988. ¡Aquí... Zaragoza! Tomo VI: 42 Zaragoza: Caja de Ahorros de la Inmaculada.

91 Citado en Fernández Clemente, E. 1995. Gente de Orden. Aragón durante la Dictadura de Primo de Rivera (1923-1930). Tomo I. La Política, Zaragoza, 1995: 219-227 Zaragoza: Caja de Ahorros y Monte de Piedad de Zaragoza, Aragón y Rioja.

92 Para la biografía del dictador ver Preston, P. 2006.Franco, «Caudillo de España»: 74 Barcelona: Mondadori.

${ }^{93}$ Fernández Clemente, E. 1995: 223. 
historia, el ejército y la nación recubrían simbólicamente aquella ceremonia en la que el Arzobispo Domenech, firmante de la Carta Colectiva de 1937, recordó a los cadetes "que desde ahora son soldados de un ejército celestial; que servirán a la Patria y a la Religión". ${ }^{94}$

En los últimos estertores del régimen se produjo una intensa campaña de propaganda para sufragar las obras del Pilar que situaría al templo en primera plana nacional. El 20 de mayo de 1930, el Arzobispo de Zaragoza, Rigoberto Domenech publicaba una circular que iba a tener una gran resonancia por lo dramático de su título " $i$ Se hunde el templo de Nuestra Señora del Pilar!". En este llamamiento, se incidía en una lectura nacionalcatólica al recordar que este templo:

es forja de virtudes de la raza, y llama inextinguible de nuestra fe dos veces milenaria, y columna de nuestra firmeza, y vena viva de toda inspiración, de toda sabiduría, de todo heroísmo, de toda santidad, de toda acción fecunda; el corazón mismo del alma de Aragón, de este Aragón que sabe bien ciertamente que en tanto subsistirá como pueblo, con sus características raciales, en cuanto vea reflejada la gallarda traza de las torres de su Templo Mariano, en el espejo rumoroso de su río, padre de España. ${ }^{95}$

En realidad, la necesidad de consolidar el templo del Pilar se venía advirtiendo desde hacía ya tiempo y Rigoberto Domenech simplemente acertó con la manera de expresarlo. La campaña publicitaria fue un auténtico éxito ya que a los quince días se había llegado a un millón de pesetas y el 14 de abril de 1931 se alcanzaban los 3.490 .000 pesetas. $^{96}$

Por último, aunque de manera muy sumaria, habría que destacar la importancia que tendrían las políticas secularizadoras durante la Segunda República en la posterior utilización del Pilar durante el franquismo. En Zaragoza, el Pilar se convirtió en un símbolo de primer orden para movilizar a la población electoralmente, tanto el templo como la plaza congregaron actos y manifestaciones en contra del gobierno y

${ }^{94} E P, 29 / 06 / 1929$

95 Archivo de la Diputación Provincial de Zaragoza (ADPZ), Diputación Central, Varios, caja 1670.

96 LACMZ, 12.04.1926, fols. 116-119 y 6.06.1930. fol. 308; y Archivo Diocesano de Zaragoza. Modulo 15,3. Junta de Obras de El Pilar. Liquidaciones de Arquitecto. 1931. Exp. 1-76. Véase asimismo Blasco ljazo, J. 1988. ¡Aquí... Zaragoza! Cuarenta Reportajes. Tomo I: 15-27 Zaragoza: Caja de Ahorros de la Inmaculada y Rincón, W. 2007. "El templo de Nuestra Señora del Pilar: Historia, Arte y Devoción. Una aproximación (1883-2007)", en J. Enrique Pasamar Lázaro y W. Rincón, Monumentum Laudis. CXXXV Aniversario de la revista El Pilar (Catálogo de la exposición): 77-93. Zaragoza: CAI-ASC. 
las medidas laicas. Entre otros muchos ejemplos, resulta especialmente reveladora la retirada de la imagen del Pilar de la sala de reuniones del Ayuntamiento en febrero de 1932 ya que por un lado, produjo una intensa movilización de los católicos, especialmente de las mujeres que recogieron 30270 firmas en contra sólo entre las zaragozanas. Por otro lado, la imagen pasó a representar el agravio republicano y tras el golpe de estado del 18 de julio de 1936, la ceremonia de restitución de la imagen del Pilar en el Ayuntamiento sería significativamente la primera ceremonia pública de las autoridades sublevadas en la que se volverían sobre los discursos pilaristas históricos, militaristas y martiriales. ${ }^{97}$

\section{CONCLUSIÓN}

A lo largo de esta artículo hemos visto como la declaración del Pilar como basílica de la Raza y Templo de la nación suponía la culminación de un largo proceso de nacionalización. Así, esta concesión de honores no puede explicarse simplemente por el carácter popular de su devoción ni tampoco por la propia politización de las devociones durante la Segunda República y la Guerra Civil. Para comprender verdaderamente esta elección debemos retrotraernos al siglo XIX, momento en el que la basílica del Pilar comenzó a adquirir toda una serie de nuevos significados. En el fondo, este proceso era una respuesta moderna de los católicos al anticlericalismo y la secularización que cuestionaban la definición religiosa de la nación. De esta manera, la nacionalización del Pilar se puede insertar en una estrategia de reestructuración global del rol de la Iglesia en las sociedades modernas.

Una vez aceptada la idea de nación en clave providencial y potenciados los cultos marianos tras la Ineffabilis Deus, la basílica comenzó a articularse en templo de la memoria española. Así, desde las obras del Pilar hasta la coronación canónica de 1905, se subrayó el carácter católico de España a través de la reconfiguración del culto a la Virgen. En paralelo, se fue vinculando su patrocinio con las grandes gestas patrióticas como la Guerra de la Independencia para recalcar su importancia histórica en el devenir de la nación. Templo histórico de España, todavía quedaba por estrechar sus vínculos con el ejército, lo que se logró a través del Centenario de los Sitios, la Academia Militar y las Campañas de África. De esta manera, el Pilar contribuía a su configuración, reforzando el relato de los orígenes míticos del catolicismo en España y atravesando desde allí las mayores gestas de la historia nacional se proyectaba hacia el futuro como templo de la nación española.

${ }^{97}$ Ver Ramón Solans, F.J. 2012. 
El caso del templo del Pilar muestra cómo el catolicismo no sólo no obstruyó sino que contribuyó a articular una particular visión de la nación española. La nacionalización de su basílica no resulta incompatible con la articulación de otras identidades colectivas en la Península ibérica. Así lo demuestran los casos de otros símbolos religiosos como Covadonga, Montserrat o Begoña. Por otra parte, si analizamos el ejemplo del Pilar a escala europea observamos cómo, lejos de ser un fracaso, constituye uno de los ejemplos más acabados de nacionalización de un símbolo religioso. ${ }^{98}$ De hecho, el santuario más importante del siglo XIX europeo, Lourdes, sólo llega a adquirir una dimensión nacional equiparable durante la instalación de la Tercera República francesa y la Primera Guerra Mundial. ${ }^{99}$

\section{BIBLIOGRAFIA}

Adagio, C. 2004. "Una liturgia per una nazione cattolica. La Chiesa spagnola e le letture provvidenzialiste della dittatura (1923-1930)", en D. Menozzi y R. Moro (ed.), Cattolicesimo e totalitarismo. Chiese e culture religiose tra le due guerre mondiali (Italia, Spagna, Francia): 171-196 Brescia: Morcelliana.

Adagio, C. 2004. Chiesa e nazione in Spagna. La dittatura di Primo de Rivera (1923-1930). Milán: Unicopli.

Álvarez Junco, J. 2006. "El conservadurismo español: entre religión y nación", en L. Castells (ed.), Del territorio a la nación Identidades territoriales y construcción nacional: 3964 Madrid: Biblioteca Nueva.

Andézian, S. 2010, "Introduction: procès de fondation", Archives des Sciences Sociales des Religions 151: 9-23.

Augé, M. 2008. Los «no lugares» espacios del anonimato. Una antropología de la sobremodernidad: Barcelona: Gedisa.

Balandier, G. 1993. El desorden. La teoría del caos y las ciencias sociales. Elogio de la fecundidad del movimiento: Barcelona: Gedisa.

${ }^{98}$ Para la idea de Fracaso ver Cueva Merino, J. 2000: 63. Un análisis del Pilar junto con otros símbolos de carácter nacional en Ramón Solans, F. J. 2012.

${ }^{99}$ Harris, R. 1999 y Lavigne, A. J. 1996. Lourdes et le Saint-Siège: Les relations de la Papauté et de la "Rome Marial": 1900-1985. Université de Pau et de Pays de l'Adour: Pau. 
Barrachina, M.A. 2000. "12 de Octubre: Fiesta de la raza, Día de la Hispanidad, Día del Pilar, Fiesta Nacional", Bulletin d'histoire contemporaine de l'Espagne, 30-31: 119-134.

Bayly, C. A. 2010. El nacimiento del mundo moderno 1789-1914. Conexiones y comparaciones globales. Madrid: Siglo XXI.

Blackbourn, D. 1993. Marpingen. Apparitions of the Virgin Mary in bismarckian Germany: Oxford: Oxford University Press.

Blasco ljazo, J. 1988. ¡Aquí... Zaragoza! Tomo VI. Zaragoza: Caja de Ahorros de la Inmaculada.

Blasco ljazo, J. 1988. ¡Aquí... Zaragoza! Tomo I. Zaragoza: Caja de Ahorros de la Inmaculada

Boyd, C.P. 2000. Historia Patria. Política, historia e identidad nacional en España: 1875-1975. Barcelona: Editorial Pomares-Corredor.

Boyd, C.P., 2007. "Paisajes míticos y la construcción de las identidades regionales y nacionales: el caso del Santuario de Covadonga", en C. P. Boyd (coord.), Religión y política en la España contemporánea: 271-294 Madrid: Centro de Estudios Políticos y Constitucionales, 2007, pp. 271-294.

Bruley, Y. 2002. "La romanité catholique au XIXe siècle: un itinéraire romain dans la littérature française", Histoire, Économie et Société 21: 59-70.

Burdiel, I. 2003. "La consolidación del liberalismo y el punto de fuga de la monarquía (1843-1870)", en M. Suárez Cortina (ed.) Las máscaras de la libertad. El liberalismo español 1808-1950: 101-133 Madrid: Marcial Pons.

Callahan, W.J. 1989. Iglesia, poder y sociedad en España, 17501874. Madrid: Nerea.

Callahan, W. 2002. La Iglesia Católica en España (1875-2002). Barcelona: Crítica.

Cenarro Lagunas, A. 1997. "La reina de la hispanidad: fascismo y nacionalcatolicismo en Zaragoza, 1939-1945", Revista de Historia Jerónimo Zurita 72: 91-101.

Certeau, M. 2007. El lugar del otro. Historia religiosa y mística. Madrid: Katz. 
Clarck, C. y Kaiser, W. 2003. Culture wars. Secular-Catholic Conflict in Nineteenth Century Europe: Cambridge: Cambridge University Press.

Cruz, R. 2005. "Old symbols, new meanings: mobilizing the rebellion in the summer of 1936", en C. Ealham y M. Richards (eds.), The Splintering of Spain. Cultural History and the Spanish Civil War, 19361939: 159-176 Cambridge: Cambridge University Press.

Cueva Merino, J. 2000. "Católicos en la calle: la movilización de los católicos españoles, 1899-1923”, Historia y Política 3: 55-79.

Cueva Merino, J. y Montero, F. 2000. "Clericalismo y anticlericalismo en torno a 1898. Percepciones recíprocas", en R. Sánchez Mantero (ed.), En torno al "98". España en el tránsito del siglo $X I X$ al siglo XX. Tomo II: 49-64 Huelva: Prensas de la Universidad de Huelva.

Di Febo, G. 1988. La Santa de la Raza. Teresa de Ávila: un culto barroco en la España franquista (1937-1962), Barcelona: Icaria.

Di Febo, G. 2002. Ritos de guerra y de victoria en la España Franquista. Bilbao: Desclée de Brouwer.

Drochon, J.E. 1890. Histoire illustrée des pèlerinages français de la très sainte Vierge : París : E. Plon, Nourrit et Cie.

Eliade, M. 1998. Le sacré et le profane. París: Gallimard.

Fernández Clemente, E. 1995. Gente de Orden. Aragón durante la Dictadura de Primo de Rivera (1923-1930). Tomo I. La Política, Zaragoza, 1995: 219-227 Zaragoza: Caja de Ahorros y Monte de Piedad de Zaragoza, Aragón y Rioja.

Forcadell Álvarez, C. 1997. Historia de Zaragoza. Zaragoza en el siglo XIX (1808-1908): 45-78 Zaragoza: Ayuntamiento de Zaragoza.

Forcadell Álvarez, C. 2008. "El Centenario de los Sitios y la Exposición Hispano-Francesa. Políticas de la memoria en la Zaragoza de 1908", Libro de Oro de la Exposición Hispano Francesa de 1908: 1-21 Zaragoza: Institución «Fernando el Católico».

Fuente Monge, G. 2001. "El enfrentamiento entre clericales y revolucionarios en torno a 1869", Ayer 44: 127-150. 
Gentile, E. 2007. Fascismo di pietra: Roma: Laterza.

Gough, A. 1996. Paris et Rome, Les catholiques français et le pape au XIX ${ }^{e}$ siècle París : Les éditions de l'Atelier/Éditions ouvrières.

Gugelot, F. 2010. "Les deux faces de Lourdes. Lourdes de Zola et Les foules de Huysmans". Archives des Sciences Sociales des Religions 151: 213-228.

Gutiérrez Lasanta, F. 1978. Historia de la Virgen del Pilar. Tomo VII: España y la Virgen del Pilar. Zaragoza: Noticiero.

Halbwachs, M. 2008. La topographie légendaire des évangiles en Terre Sainte:124-128 París : PUF.

Hammon, A. 1866. Notre Dame de France où l'histoire du culte de la sainte vierge en France, depuis l'origine jusqu'à nos jours: París: Henri Plon

Harris, R. 1999. Lourdes. Body and Spirit in the Secular Age. Londres: Penguin Book.

Hastings, A. 2000. La construcción de nacionalidades: etnicidad, religión y nacionalismo: 237 Madrid, Cambridge University Press.

Haupt, H.-G. y Langewiesche, D. (eds.). 2010. Nación y religión en Europa. Sociedades multiconfesionales en los siglos XIX y XX: Zaragoza: Institución «Fernando el Católico».

Hollander, P. y Langlois, C. (dirs.) 2011. Foules catholiques et régulation romaine. Les couronnements des vierges de pèlerinages à l'époque contemporaine: Limoges : Pulim.

Horaist, B. 1995. La Dévotion au Pape et les catholiques français sous le pontificat de Pie IX (1846-1878). D'après les Archives de la Bibliothèque Apostolique Vaticane: 9-22 Roma: École Française de Rome.

Hunt, L. 1984. Politics, Culture and Class in the French Revolution. Berkeley: University of California Press.

Jardiel, F. 1902. La Virgen del Pilar y su templo. Crónica oficial de las nuevas obras del templo metropolitano de Nuestra Señora del Pilar. Zaragoza: Mariano Salas. 
Jardiel, F. 1920. Algunos sermones, discursos, artículos y poesías. Zaragoza: Salvador Hermanos.

Jonas, R. 2000. France and the Cult of the Sacred Heart. An Epic Tale for Modern Times: Los Angeles: University of California Press.

Langlois, C. 1997. "Notre Dame de France (1860), Modernité et identité le succès et l'échec", en E. Fattorini (dir.) Santi, culti, simboli nell'età della secolarizzazione (1815-1915): 301-329 Roma: Rossenberg \& Sellier.

Langlois, C. 2000. "La conjoncture mariale des années quarante", en F. Angelier y C. Langlois (eds.), La Salette. Apocalypse, pèlerinage et littérature (1846-1996). Actes du colloque de l'Institut catholique de Paris (29-30 de novembre de 1996): 21-38 Grenoble : Jérôme Million.

Langlois, C. 2005. "Le temps de l'immaculée conception. Définition dogmatique (1854) et événement structurant", en B. Bérthouart y A. Lottin (coords.), La dévotion mariale de l'an mil à nos jours: 366-379 Arras: Artois Presse Université.

Lavigne, A. J. 1996. Lourdes et le Saint-Siège: Les relations de la Papauté et de la "Rome Marial": 1900-1985. Université de Pau et de Pays de l'Adour: Pau.

Louzao Villar, J. 2008. "«Es deber de verdadero y auténtico patriotismo...»: la nacionalización del conflicto entre clericales y anticlericales (1898-1939)", M.E. Nicolás Marín y C. González Martínez (coord.), Ayeres en discusión (recurso electrónico): 73 Murcia: Universidad de Murcia.

Louzao Villar, J. 2011. Soldados de la fe o amantes del progreso. Catolicismo y modernidad en Vizcaya (1890-1923). Logroño: Genueve.

Louzao Villar, J. 2013. "Nación y catolicismo en la España contemporánea. Revisitando una interrelación histórica". Ayer 90: 65-89.

Magaña Soria, A. 1906. Crónica de las solemnes fiestas que se celebraron en Zaragoza con motivo del Fausto suceso de la Coronación Canónica de la Imagen de Nuestra Señora del Pilar y de la Peregrinación Nacional a su Basílica. Zaragoza: Mariano Salas.

Marcilhacy, D. 2010. Raza hispana. Hispanoamericanismo e imaginario nacional en la España de la Restauración. Madrid: Centro de Estudios Político Constitucionales. 
Michonneau, S. 2007. Barcelona. Mémoire et identité. 1830-1930: Rennes: Presses Universitaires de Renne.

Moneva y Pujol, J. 1952. Memorias. Zaragoza: Noticiero.

Moreno Luzón, J. 2004. "Entre el progreso y la Virgen del Pilar. La Pugna por la memoria en el centenario de la Guerra de la Independencia", Historia y política 12: 41-78.

Moreno Mazón, J. 1880, Sermón predicado por el Ilmo. Sr. Dr. José Moreno Mazón en el templo metropolitano del Pilar de Zaragoza el 17 de abril del presente año de 1880. Cuenca: Imp. de Casimira Madina.

Mosse, G.L. 2005. La nacionalización de las masas. Simbolismo político y movimientos de masas en Alemania desde las Guerra Napoleónicas al Tercer Reich. Madrid: Marcial Pons.

Navarro, F. 1906. El monumento a los Sitios con el templo del Pilar de Zaragoza. Zaragoza: Mariano Salas.

Nougués y Secalll, M. 1862. Historia crítica y apologética de la Virgen nuestra señora del Pilar de Zaragoza y de su templo y tabernáculo desde el siglo I hasta nuestros días: VI-XI Madrid: Imprenta de Alejandro Gómez Fuentenebro.

Núñez Seixas, X.M. 2006. ¡Fuera el invasor! Nacionalismo y movilización bélica durante la guerra civil española (1936-1939). Madrid: Marcial Pons.

Peiró Martin, I. 2008. La Guerra de la Independencia y sus conmemoraciones (1908, 1958 y 2008). Zaragoza: Institución «Fernando el Católico».

Peiró Martín, I. y Rújula López, P. 2000. "Representaciones calculadas: La imagen de Aragón en el siglo XX", en C. Forcadell (coord.), Trabajo, sociedad y cultura. Una mirada al siglo XX en Aragón: 275-301 Zaragoza: Publicaciones Unión.

Pérez, N. 1930. Apuntes históricos de la devoción a Nuestra Señora La Santísima Virgen del Pilar. Zaragoza: Imprenta "La Editorial".

Preston, P. 2006.Franco, «Caudillo de España»: 74 Barcelona: Mondadori. 
Quiroga Fernández de Soto, A. 2008. Haciendo españoles. La nacionalización de las masas en la Dictadura de Primo de Rivera (19231930). Madrid: Centro de Estudios Políticos Constitucionales.

Ram de Viu, L. 1908,. "Mi corona”, en F. Jardiel, Álbum poético de la Virgen Santísima del Pilar: 135 Zaragoza: Mariano Salas.

Ramón Solans, F.J., 2011. "«Como Español y católico» los efectos del proceso de contrucción nacional de la Virgen del Pilar", en A. Barrio Alonso, J. Hoyos Puentes y R. Saavedra Arias (coords.), Nuevos horizontes del pasado: culturas políticas, identidades y formas de representación: 9 Santander: Publican.

Ramón Solans, F.J. 2011b. "La restructuración del culto al Pilar. La peregrinación de 1880, un proyecto nacional", en C. Frías, J.L. Ledesma y J. Rodrigo (eds.), Reevaluaciones. Historias locales y miradas globales. Actas del VII Congreso de Historia Local de Aragón: 283-292 Zaragoza, Institución «Fernando el Católico».

Ramón Solans, F.J., 2011c. "Le couronnement de la Vierge del Pilar en 1905: une alliance scellée entre le projet national conservateur et le catholicisme", en P. Hollander y C. Langlois (dirs.), Foules catholiques et régulation romaine. Les couronnements des vierges de pèlerinages à l'époque contemporaine : 177-188 Limoges : Pulim, 2011.

Ramón Solans, F. J. 2012. "Movilización, política y nación. Una aproximación historiográfica a los cultos marianos en época contemporánea", Amnis. Revue de civilisation contemporaine Europes/Amériques, 11.

Ramón Solans, F.J. 2014. La Virgen del Pilar dice... Usos políticos y marianos de un culto mariano en la España contemporánea. Zaragoza: Prensas de la Universidad de Zaragoza.

Rincón, W. 2007. "El templo de Nuestra Señora del Pilar: Historia, Arte y Devoción. Una aproximación (1883-2007)", en J. Enrique Pasamar Lázaro y W. Rincón, Monumentum Laudis. CXXXV Aniversario de la revista El Pilar (Catálogo de la exposición): 33-166. Zaragoza: CAI-ASC.

Salomón Chéliz, M.P. 2002. Anticlericalismo en Aragón. Protesta popular y movilización política (1900-1939). Zaragoza: Prensas Universitarias de Zaragoza.

Smith, A.D. 2008. Chosen Peoples. Sacred Sources of National Identity: Oxford: Oxford University Press. 
Soldevila y Romero, J. 1906. Pastoral de.... con respecto a los Sitios de Zaragoza: 13-14 Zaragoza: Mariano Salas.

Sorrel, C. 2001. "Ultramontanisme et culte marial: les fêtes de las promulgation du dogme de l'immaculée Conception dans le duché de Savoie (1855)", en P. d'Hollander (ed.), L'Église dans la rue. Les cérémonies extérieures du culte en France au XIX siècle. Actes du colloque des 23-24 mars 2000 à Limoges : 229-242 Limoges: Pulim.

Suárez Cortina, M. 2008. "Catolicismo,identidad nacional y libertad religiosa en la España liberal”, en J. Beramendi y M.J. Baz, Identidades y memoria imaginada: 223-261 Valencia: PUV, 2008

Sudjic, D. 2005. La arquitectura del poder. Cómo los ricos y poderosos dan forma a nuestra mundo. Barcelona: Ariel.

Vilallonga, B. 2012. "La nación católica: Balmes y la representación de España en el ochocientos, Historia Social 72: 49-64. 